\title{
Taxonomic and phylogenetic composition show biotic resistance to exotic invasion in acid seep springs
}

\author{
David F. Barfknecht ${ }^{*}$ (D) and David J. Gibson@
}

\begin{abstract}
Background: Few studies have incorporated the evolutionary insights provided by analysis of phylogenetic structure along with community composition to assess the effects of exotic invasion on freshwater wetlands. Here, we assess the taxonomic and phylogenetic relationships among acid seep springs to investigate the potential homogenization or resistance of communities due to invasion of an exotic grass.

Results: Multivariate community analyses indicated differences in community and phylogenetic composition and dispersion among acid seep springs, associated with gradients in soil moisture, canopy cover, and phylogenetic diversity. By contrast, univariate analyses showed differences in taxonomic diversity but not phylogenetic diversity among acid seep springs.

Conclusions: Despite exotic invasion, individual acid seep springs remained taxonomically and phylogenetically distinct from each other. Taxonomic and phylogenetic diversity metrics revealed different aspects of composition, reinforcing the importance of including both in analyses of plant communities for understanding community assembly following exotic invasion and for management purposes. Within acid seep springs, taxonomic and phylogenetic composition appear to be driven more through environmental filtering by light and moisture than by the competitive effects following invasion of an exotic grass in support of Elton's biotic resistance hypothesis.
\end{abstract}

Keywords: Acid seep springs, Diversity, Community, Phylogenetics, Exotic invasion, Environmental filtering, NMDS, UniFrac, Vector analysis

\section{Background}

Exotic plant invasions are a leading global concern for ecologists, biologists, and the general public (D'Antonio and Flory 2017). These species invade native communities due to natural and (increasingly) anthropogenic causes (González-Moreno et al. 2014). The introduction of exotic species results in declines in ecosystem functioning and alterations of ecosystem services (Strayer 2012). In addition, risks and consequences associated with exotic invasion may shift due to co-occurring climatic changes (Walther et al. 2009). While exotic species can alter ecosystem functioning, shifts in environmental

\footnotetext{
* Correspondence: david.barfknecht@siu.edu

School of Biological Sciences, Southern Illinois University - Carbondale, Carbondale, IL 62901-6509, USA
}

\section{Springer Open}

filtering and their effect on native species composition can facilitate or hinder invasion success. Studies have shown that, in general, exotic species frequently establish better in previously uninvaded habitats compared to in their native habitats, often by competitively excluding native species (Warren et al. 2011).

Along with economic and ecosystem service concerns, exotic invasion may decrease native taxonomic (i.e., species) diversity and result in decreased compositional differences between invaded locations (i.e., biotic homogenization; D'Antonio and Vitousek 1992; Yannelli et al. 2017). This process of biotic homogenization has been explored not only based on taxonomic diversity losses, but also genetic and functional losses (Olden et al. 2004; Olden and Rooney 2006). These studies note how 
homogenization can increase the susceptibility of communities to further exotic invasion while also accelerating the loss of rare taxa. In comparison, the biotic resistance hypothesis (Elton 1958; Levine and D'Antonio 1999) suggests that high diversity communities are more resistant than low diversity communities to exotic species invasions and less susceptible to biotic homogenization. Ultimately, all of these ecological processes can result in changes in diversity and community assembly patterns across large scales (Rooney et al. 2007). Given these concepts, exotic invasions lead to both declines in native diversity as well as increased similarity of sites, which all have been observed to occur simultaneously in forest understory communities (Rooney et al. 2004).

The biotic resistance hypothesis, as proposed by Elton (1958), highlights that exotic species must overcome the resistance of a particular ecosystem to establish and incorporate into a local assemblage. Greater biotic resilience to exotic invasive species is typically associated with communities that exhibit higher diversity compared with lower diversity communities (Davis 2003). Therefore, communities with fewer species are often considered more susceptible to exotic invasion than those communities with more species (Elton 1958; Fox and Fox 1986; Pimm and Pimm 1991; Rejmánek 1996; Byers and Noonburg 2003; Parker and Hay 2005; Von Holle 2005). In addition, once local communities experience exotic invasion across a large spatial extent, they may experience a reduction in ecological and evolutionary distinctiveness (i.e., beta-diversity loss, biotic homogenization; Olden et al. 2004). Nonetheless, these two processes (high local community susceptibility to invasion and the subsequent lack of between site distinctiveness) may be interactive in natural systems during exotic invasion (Ricciardi 2001; Odegard 2017).

The acid seep springs of the Cretaceous Hills region (Shawnee National Forest, IL, USA) have experienced both invasion of the exotic Microstegium vimineum (Trin.) A. Camus (Japanese stilt grass; Nepalese browntop) between 1968 and 2008 (Schwegman 1969; Basinger 2009; Barfknecht et al. 2020) and stream down-cutting, exemplifying both changing biotic and abiotic conditions, respectively. Acid seep springs are discrete groundwater discharge wetlands with acidic water and substrates which support diverse and unique plant communities compared to the adjacent hardwood forest understory (Voigt and Mohlenbrock 1964), analogous to the upland, xeric glades, and barrens in the region (Heikens and Robertson 1995). While acid seep springs have been observed and surveyed elsewhere (Homoya et al. 1984; Cranfill 1991), acid seep springs of the Cretaceous Hills region hold high intrinsic value within Illinois, based on their unique floristics and physical geography. Herbicide and fire treatments can help control M. vimineum within these acid seep springs, but such treatments have not been maintained since 2014 and often prove to be largely ineffective (Southern Illinois Invasive Plant Strike Team 2019). This lack of management may have led to increases in M. vimineum abundance as well as drastic changes in native flora (loss of species, altered community composition, etc.). Stream down-cutting results in deep narrow channels, with adjacent stream sides drying up due to a locally lowered water table (Merten et al. 2016). As the streambed lowers, the water table recedes and can desiccate wetlands and adjacent terrestrial habitats, altering plant communities and leading to the establishment of more mesic and xeric flora (Springer et al. 2015).

Microstegium vimineum is an annual, $\mathrm{C} 4$ allelopathic exotic invasive grass native to Asia that establishes in dense patches within edges and the understory of deciduous forests following disturbance (Horton and Neufeld 1998; Gibson et al. 2002; Pisula and Meiners 2010). This exotic invasive grass develops both cleistogamous (closed for self-fertilization) and chasmogamous (open for outcrossing) flowers at anthesis and can also spread clonally via adventitious rooting at nodes (Huebner 2007). These features allow $M$. vimineum to competitively exclude native flora by inhibiting species germination and competing for light, ultimately changing taxonomic composition and productivity (Leicht et al. 2005; Flory et al. 2007; Oswalt et al. 2007; Flory and Clay 2010). Once established, populations of this invasive grass can rapidly increase in size and competitively exclude native species within 3-5 years. In support, dense monocultures of this species within forest understories have been shown to alter taxonomic and phylogenetic diversity and composition (Leicht et al. 2005). Mechanical removal, prescribed fire, and herbicide treatments can be ineffective at controlling $M$. vimineum populations if not at an appropriate time or frequency (Flory and Lewis 2009; Ward and Mervosh 2012; Frey and Schmit 2015) and can damage native plant communities with both rare and sensitive species (Emery et al. 2013).

We hypothesized that despite exotic invasion of $M$. vimineum, the floristically rich acid seep spring communities would remain taxonomically and phylogenetically distinct from each other, consistent with Elton's biotic resistance hypothesis (Elton 1958) and opposed to the biotic homogenization hypothesis. In addition, we predicted that acid seep spring communities would exhibit compositional differences based on both environmental variables and taxonomic and phylogenetic indices, again regardless of the presence of $M$. vimineum (again, consistent with Elton's biotic resistance hypothesis and opposed to the biotic homogenization hypothesis). A study, such as this, of taxonomic and phylogenetic diversity, composition, and environmental variables of acid seep 
springs will aid in understanding how exotic invasions impact plant communities.

\section{Methods \\ Vegetation surveys}

Within each of 10 acid seep springs (Fig. S1), $201-\mathrm{m}^{2}$ plots were established between June and August 2017 in locations where the substrate supporting vegetation was inundated with groundwater seepage. Plots were randomly established along transects following the direct drainage paths of each acid seep spring, alongside of the central stream, and a random distance (in meters) from the stream outlet in each seep. The plots were flagged, and their location recorded using a GPS to allow relocation. While $1-\mathrm{m}^{2}$ plots may be small for surveying woody species, our focus was on the herbaceous layer vegetation, and this size was chosen to ensure sufficient within-seep replication for appropriate statistical analysis. Plots established on bare soil or rock with no vegetation or in vegetation unaffected by adjacent seepage were not surveyed and replaced with another randomly selected plot. To estimate species abundance, herbaceous and woody species rooted in the plots were assigned cover classes values based on a modified Daubenmire scale (Daubenmire 1959; Bonham et al. 2004). Seven cover classes were used based on the following size bins: $1=$ less than $1 \%, 2=1-5 \%, 3=5-25 \%$, $4=25-50 \%, 5=50-75 \%, 6=75-95$, and $7=95-100 \%$. Vouchers were collected for vascular plant species encountered and are deposited in the herbarium at Southern Illinois University-Carbondale (SIUC). Species richness and Shannon-Weiner diversity indices for plot-based and entire site-based data were calculated using the vegan (Oksanen et al. 2007) package in $\mathrm{R}$ software (version 3.4.2, R Core Team 2015).

\section{Environmental data collection}

Environmental variables were collected between May and August 2017. Soil moisture was measured in June, July, and August at each spring using a soil moisture probe (ECH2OEC-5 Model, METER Group, Inc., Pullman, WA, USA). Percent overhead canopy cover was recorded in several random locations within each spring using a convex spherical crown densiometer (Model-C, Forestry Suppliers, Inc., Jackson, MO, USA). Light conditions were monitored during the collection of community data as photon flux density of photosynthetically active radiation (PAR) at $1 \mathrm{~m}$ above ground within three random plots of each spring using a light meter (Model LI-190a, Li-COR, Inc., Lincoln, NE, USA), and compared to readings in a nearby open canopy area to calculate relative PAR. All PAR measurements were taken between $10 \mathrm{am}$ and $2 \mathrm{pm}$ on cloud-free days. Slope (\%) was measured for each spring using a clinometer (Suunto, PM5/
360PC). Three separate soil $10 \mathrm{~cm}$ cores were extracted from three randomly selected plots within each spring. Soil acidity $(\mathrm{pH})$ and conductivity $(\mathrm{mV})$ of each soil sample were measured using a conductivity probe (Accumet, Model AP62, Fisher Scientific International, Inc., Waltham, MA, US). Samples were prepared as 1:1 soil:distilled water slurries before acidity and conductivity measurements were taken. Samples from the soil cores were used to assess soil organic matter (\%) as loss-onignition in a furnace (Thermodyne, Fisher-Scientific, Inc., Waltham, MA, US) at $550{ }^{\circ} \mathrm{C}$ for $24 \mathrm{~h}$.

\section{Phylogenetic methods}

Nucleotide sequences for $r b c L$ and $m a t K$ of species observed were accessed from Genbank (https://www.ncbi. nlm.nih.gov/genbank/) and fasta (.fas) files were compiled using Notepad++ (version 7.3). Sequences were aligned for both genes individually using Muscle alignment (Version 3.8.31; Edgar 2004) using Seaview (version 4.5.4; Gouy et al. 2010). Manual adjustment, trimming, and concatenation of $r b c l$ and matk sequences for observed species were also conducted in Mesquite (version 3.40; Maddison and Maddison 2018). Inference of a maximum-likelihood tree from the concatenated sequences and automatic best-fit model selection was done in IQ-Tree (version 1.5.5; Kalyaanamoorthy et al. 2017). The final accepted tree was required to contain no polytomies within closely related taxa or clades. Phylogenetic diversity within and among springs was assessed using net relatedness indices (NRI) and nearest taxon indices (NTI). NRI and NTI null models used to calculate expected values were based on random shuffling of taxa based on both community and phylogenetic distance matrices. Operations for individual tree pruning for individual seeps, generation of NRI and NTI values, were performed in R software with ape (Paradis et al. 2004) and picante (Webb et al. 2008) packages.

\section{Univariate analyses}

One-way analyses of variance (ANOVAs) were used to compare species richness, Shannon-Weiner diversity $(H$ '), and phylogenetic diversity (NRI and NTI values) among acid seeps using plot-based species abundance data. Tukey's least squared differences (Tukey's LSD test) were also used to investigate pairwise relationships of these diversity indices among individual springs when ANOVA results showed significance at $\alpha=0.05$. In addition, Pearson's correlations were calculated between each of these indices. All analyses were performed and calculated in R software utilizing the car (Fox and Weisberg 2011), ggplot2 (Wickham 2009), lsmean (Lenth 2016), and multicomp (Hothorn et al. 2008) packages. 


\section{Community analyses}

Species (taxonomic) abundance-weighted non-metric multidimensional scaling (TNMDS) ordinations and NMDS ordinations based on Weighted UniFrac differences from phylogenetic data (PNMDS) were generated to compare differences in community and phylogenetic composition among the acid seep springs. Abundanceweighted taxonomic composition was based on midpoints of Daubenmire cover class values per species in each plot and then averaged across each acid seep spring. Stress values and scree plots were used to determine how many dimensions were needed to display each ordination with acceptable visualization of realistic distances among acid seep spring centroids (stress values under 0.20).

For both taxonomic and phylogenetic distances, permutational analyses of variance (PERMANOVA), tests of homogeneity of dispersion (PERMDISP) and post hoc pairwise tests for multivariate analyses were used to analyze plot-based data. Significant vectors characterizing the greatest rate of change for environmental variables and entire site-based diversity indices calculated from vector analyses were included in each ordination individually. To test whether TNMDS and PNMD $\mathrm{S}$ ordinations significantly differed from each other, a symmetric Procrustes analysis was performed, using the TNMDS as the target matrix and the PNMDS as the rotation matrix. A protest analysis was used to provide a significance value for the non-randomness between both ordinations, using 999 permutations. Finally, a Mantel test was conducted for both taxonomic and phylogenetically based Bray-Curtis dissimilarity with Euclidean based distances based on GPS coordinates to determine whether closer sites were more compositionally similar. All analyses were conducted using the ape, vegan, and picante (Kembel et al. 2010) packages in R software.

\section{Results}

\section{Vegetation surveys}

Seventy-one taxa were observed in all plots sampled to determine species abundance, none of which were listed as Illinois or federally threatened or endangered (Table S1). Microstegium vimineum was the most abundant and frequent species recorded within all acid seep springs. The only other exotic invasive species observed directly within these acid seep springs were Lonicera japonica Thunb. and Rosa multiflora Thunb., both of which less frequently occurred within plots. The dominant native species were similar to those reported by Schwegman (1969; Barfknecht et al. 2020) a half century ago, save Microstegium vimineum. Native species occurring in all acid seep springs in our survey included Acer rubrum L., Athyrium filixfemina (L.) Roth, Carex crinita Lam., Corylus americana Marshall, Cornus florida L., Liriodendron tulipifera L.,
Onoclea sensibilis L., and Toxicodendron radicans (L.) Kuntze. There were 23 species appearing in only one acid seep spring.

\section{Phylogeny}

A maximum likelihood tree was created for the 71 observed taxa without any resulting polytomies between closely-related species or clades (Fig. 1). A transversion model with empirical base frequencies, which allowed for a proportion of invariable sites plus discrete Gamma model (TVM + F + I + G4; Yang 1994; Gu et al. 1995), was used to the first two partitions of matK. The last $m a t K$ partition was obtained with a general time reversible model with unequal rates and unequal base frequencies, with empirical base frequencies, which allowed for a proportion of invariable sites plus discrete Gamma model (GTR + F + I + G4; Tavaré 1986). The first partition of $r b c L$ was obtained with a symmetric model with unequal rates but equal base frequencies which allowed for a proportion of invariable sites plus discrete Gamma model (SYM + I + G4; Zharkikh 1994), while the last two were obtained using a GTR + F + I + G4 model. These models were selected via the Akaike information criterion (AIC).

\section{Univariate analyses}

Results from the one-way ANOVA for species richness showed species richness and Shannon-Weiner diversity $\left(H^{\prime}\right)$ significantly differed among acid seep springs at the plot-level (mean species richness $=6.2 \pm 0.4$ species per $\mathrm{m}^{2}, F_{9190}=3.72 ; p=0.0002$; mean $H^{\prime}=1.3 \pm 0.1$ per $\mathrm{m}^{2}$ plot, $\left.F_{9190}=2.13 ; p=0.03\right)$. Tukey's LSD post hoc tests showed that South Spring $\left(5.0 \pm 0.3\right.$ species per $\left.\mathrm{m}^{2}\right)$ had lower species richness compared to Kruger Spring (6.6 \pm 0.3 species per $\mathrm{m}^{2}$ plot; Fig. 2 a). South Spring also had lower species richness compared to Azotus $(6.7 \pm 0.4$ species per $\left.\mathrm{m}^{2}\right)$ and Klondike Springs $(6.6 \pm 0.4)$. Of the remaining acid seep springs, Baldy $(5.6 \pm 0.4$ species per $\left.\mathrm{m}^{2}\right)$, New $\left(5.8 \pm 0.4\right.$ species per $\left.\mathrm{m}^{2}\right)$, and Sphagnum Springs $\left(5.8 \pm 0.3\right.$ species per $\left.\mathrm{m}^{2}\right)$ had significantly lower species richness compared to Kruger Spring. The only two acid seep springs which were significantly different based on Shannon-Weiner Diversity were Kruger (1.4 \pm $0.1)$ and Klondike Springs $(1.3 \pm 0.1$; Fig. 2 b). Abundance-weighted phylogenetic diversity indices did not differ among seep springs (NRI mean $=-0.7 \pm 0.28$, $F_{9190}=0.81 ; p=0.61 ; N T I$ mean $=0.4 \pm 0.26, F_{9190}=$ 0.27; $p=0.98$; Fig. 2 c-d). Taxonomic diversity indices were highly significantly positively correlated $\left(r^{2}=0.64\right.$; $p<0.01$ ), while phylogenetic diversity indices were highly significantly negatively correlated $\left(r^{2}=-0.71 ; p<\right.$ 0.01 ; Table 1). In addition, species richness and NTI were significantly negatively correlated $\left(r^{2}=-0.21 ; p<0.05\right)$. 


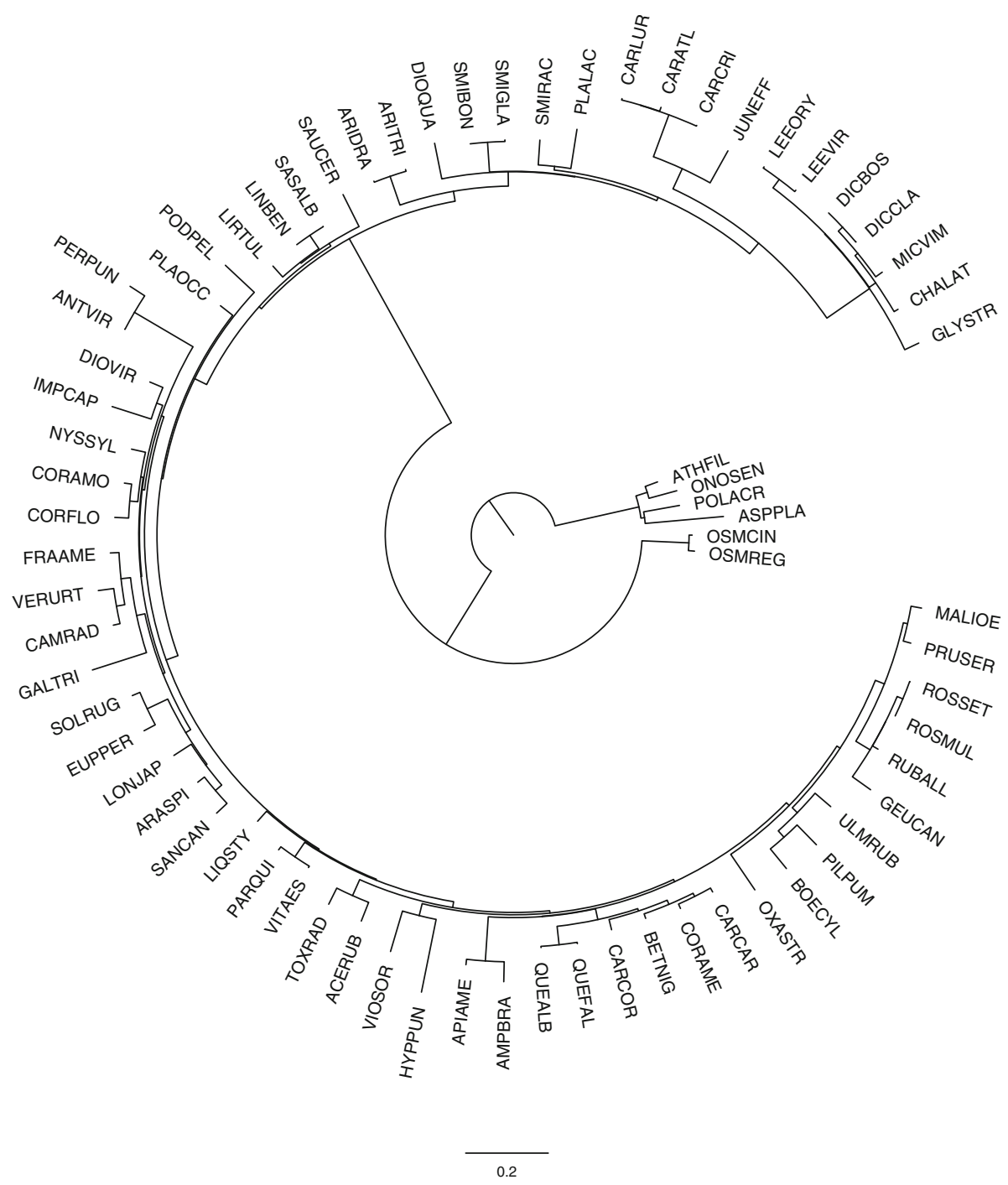

Fig. 1 Maximum likelihood phylogeny of species observed within 10 acid seep springs. The scale bar represents the substitution rate of nucleotides (at an individual locus) within concatenated $r b c L$ and matK plastid regions over the specified distance. Species codes are available in Table S1. Monilophytes are positioned as the root

\section{Community analyses}

A two-dimensional TNMDS ordination solution was retained for interpretation (stress $=0.13$; Fig. 3a). The results from the PERMDISP indicated a marginally significant difference in dispersion among acid seep springs $\left(F_{9190}=2.02, p=0.05\right)$. The PERMANOVA indicated that acid seep springs exhibited highly significant differences from each other (pseudo- $F_{9190}=0.33, p=0.01$ ). Based on pairwise ADONIS analyses, all acid seep springs were significantly different from each other $(p<$ 0.05 in all pairwise comparisons among acid seep springs).

Environmental variable and diversity vectors varied in their coefficients of determination and their trajectory within the NMDS ordination (Table 2, Fig. 3a). Soil moisture was significantly related to differences in taxonomic composition in June $\left(24.74 \pm 2.19 \%, r^{2}=\right.$ $0.81, p=0.01)$, July $\left(24.74 \pm 2.01 \%, r^{2}=0.76, p=0.01\right)$, and August $\left(32.24 \pm 2.15 \%, r^{2}=0.24, p=0.02\right)$ of 2017 . Canopy cover was the only other environmental variable significant as a vector $\left(60.26 \pm 6.15 \%, r^{2}=0.58, p=0.05\right)$. Soil moisture and canopy vectors had near-opposite trajectories within the NMDS ordination. NTI was significantly fit as a vector to the ordination $\left(0.43 \pm 0.05, r^{2}=0.66, p=\right.$ 0.03 ), indicating a gradient in phylogenetic beta-diversity across acid seep springs based on observed and expected mean nearest neighbor distances. The other diversity indices were not significantly fit as vectors to the ordination.

Two dimensions were also retained for the PNMDS ordination (stress $=0.14$; Fig. $3 \mathrm{~b}$ ). The PNMDS ordination showed differing results from the TNMDS ordination 

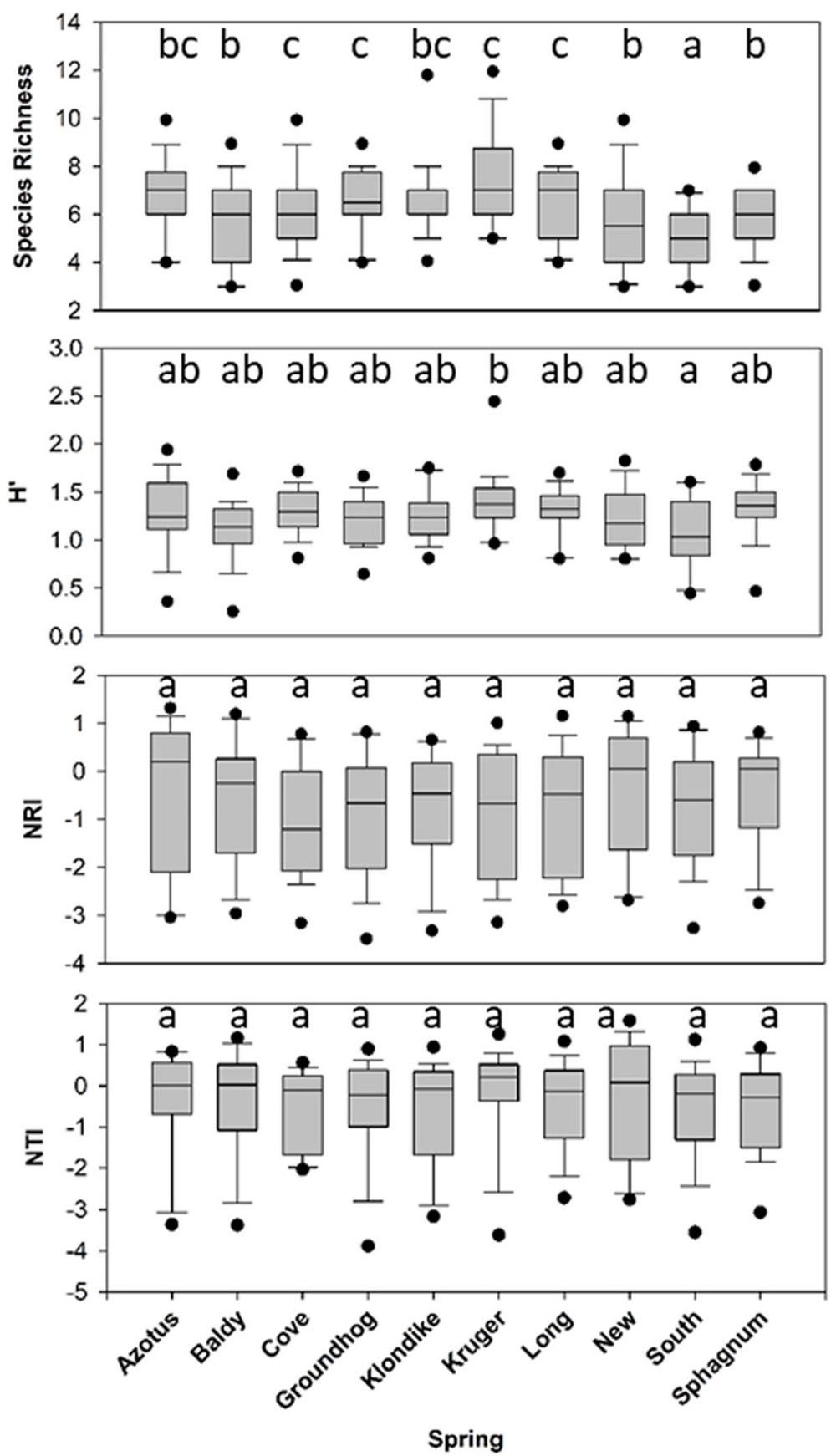

Fig. 2 Box and whisker plots of species richness (species per 1- $\mathrm{m}^{2}$ plot), Shannon-Weiner diversity $\left(H^{\prime}\right)$, net relatedness index (NR), and nearest taxon index (NTI) averaged from twenty individual $1-\mathrm{m}^{2}$ plots within each of the ten acid seep springs. Boxplots show the median (middle line within the box), interquartile range ( $25 \%$ quantile is the lower border of the box and $75 \%$ quantile is the upper border of the box), and extremes of the distribution. Acid seep springs sharing the same lowercase letter are not significantly different ( $a=005$, Tukey's LSD test)

regarding the topology of individual acid seep springs. In comparison, the PNMDS ordination placed Azotus and Groundhog Springs (as well as Sphagnum and South Springs) relatively further apart and Baldy and New Springs relatively closer together. In addition, where the
TNMDS placed Sphagnum Springs more central in the ordination, Baldy Springs became more central in the PNMDS ordination. The PERMDISP indicated a significant difference of dispersion between acid seep springs based on plot data $\left(F_{9190}=8.34, p=0.01\right)$, and results 
Table 1 Correlation matrix between species richness, ShannonWeiner, net relatedness, and nearest taxon indices $\left(S, H^{\prime}, N R I\right.$, and $N T I$, respectively). A single asterisk $\left(^{*}\right)$ indicates significant correlations $(p<0.05)$, while double asterisks $\left(^{* *}\right)$ indicate highly significant correlations $(p<0.01)$

\begin{tabular}{lllll}
\hline & $\boldsymbol{S}$ & $\boldsymbol{H}^{\prime}$ & $\mathbf{N R I}$ & $\mathbf{N T I}$ \\
\hline$S$ & 1 & & & \\
$H^{\prime}$ & $0.64^{* *}$ & 1 & & \\
NRI & -0.02 & -0.10 & 1 & \\
NTI & $-0.21^{*}$ & -0.05 & $-0.71^{* *}$ & 1 \\
\hline
\end{tabular}

from PERMANOVA indicated highly significant differences of acid seep springs from each other.

Both TNMDS and PNMDS ordinations showed similar relationships in the trajectories for environmental variables, but not phylogenetic vectors (Table 2; Fig. 3b). Canopy cover as an environmental variable (60.26 \pm $\left.6.15 \%, r^{2}=0.53, p=0.03\right)$, and June $\left(24.74 \pm 2.19 \%, r^{2}=\right.$ $0.74, p=0.01)$, July $\left(24.74 \pm 2.01 \%, r^{2}=0.63, p=0.03\right)$, and August soil moisture $\left(32.24 \pm 2.15 \%, r^{2}=0.64, p=\right.$ 0.04 ) each were significantly related to differences in phylogenetic composition, much like with differences in species composition. Unlike with species abundance, NRI $\left(24.74 \pm 2.19, r^{2}=0.74, p=0.01\right)$ instead of NTI $\left(0.43 \pm 0.05, r^{2}=0.19, p=0.49\right)$ was significantly related to differences in phylogenetic composition, indicating a gradient in phylogenetic beta-diversity across acid seep springs based on observed and expected mean pairwise distances.

Based on the Procrustes analysis, the root mean squared error (RMSE) was 0.31 , indicating a low residual error and a larger convergence between the TNMDS and PNMDS ordinations than what would be expected based on chance. This result was supported by the protest analysis, which indicated no significant difference between the TNMDS and PNMDS ordinations $(p=0.12)$. Finally, both Mantel tests based on both taxonomic $(r=-0.03 ; p=0.59)$ and phylogenetic $(r$ $=-0.08 ; p=0.42$ ) composition were not significant, indicating that acid seep springs which were closer to each other were not significantly more likely to be compositionally similar than those more distant.

\section{Discussion}

Our findings show support of our initial hypothesis and the biotic resistance hypothesis (Elton 1958; Levine and D'Antonio 1999), but there is also support for biotic homogenization hypothesis (Olden et al. 2004; Olden and Rooney 2006). Acid seep spring communities remained distinct from each other based on diversity (univariately) and community and phylogenetic composition (multivariately) regardless of
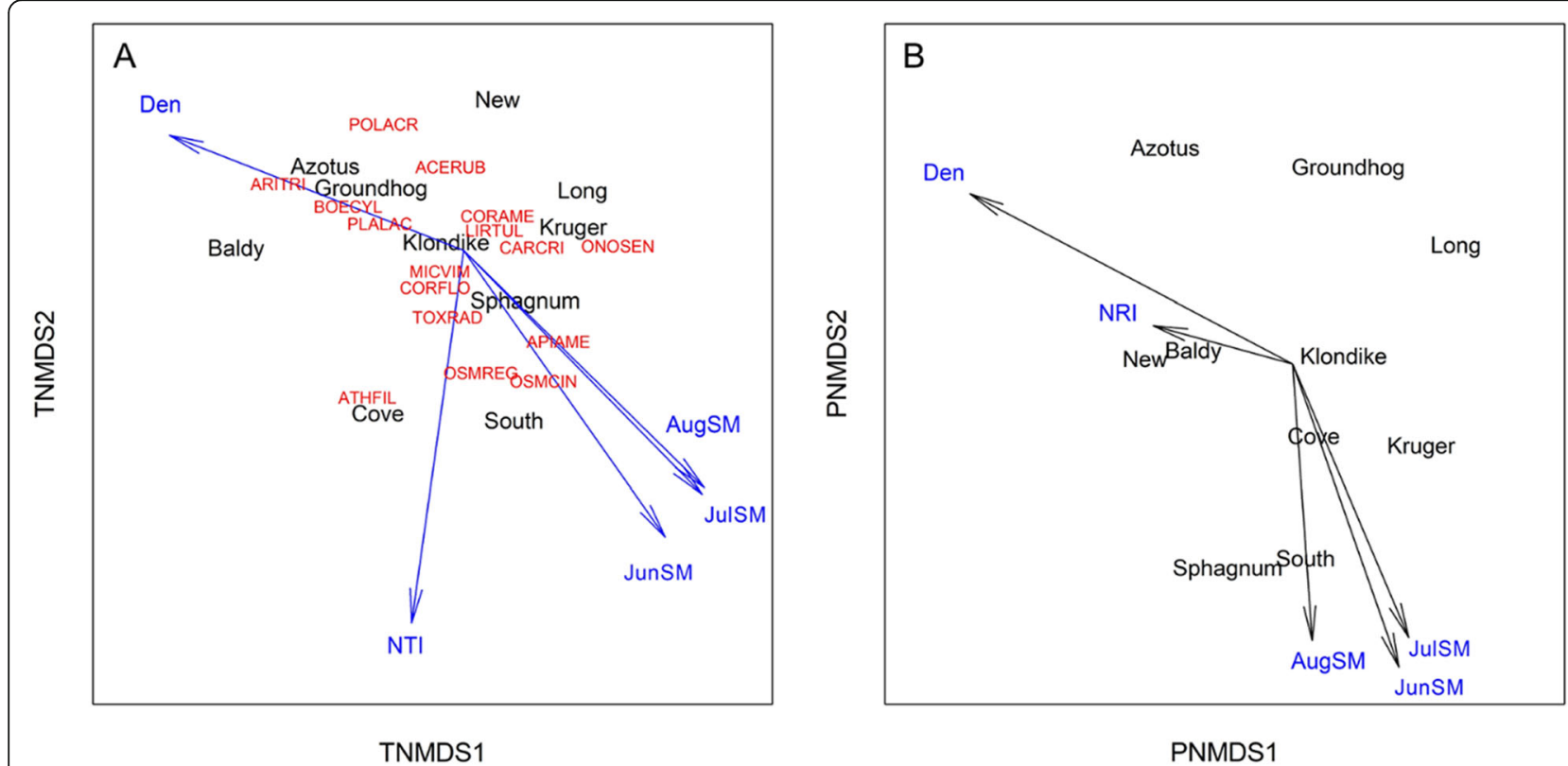

Fig. 3 Two-dimensional a TNMDS and $\mathbf{b}$ PNMDS ordinations of ten acid seep springs (names in black text shown at the position of the centroid among 10 plots per spring) based on species abundance data (species in red text; see Table S1 for codes). Only species discussed in the "Discussion" section are labeled in the TNMDS, but all recorded species were used to build both ordinations. Significant vectors from vector analysis (blue text; see Tables 1 and 2) are plotted including Den (overhead canopy cover), June, July, and August soil moisture (JunSM, JulSM, and AugSM, respectively), net relatedness index (NRI), and nearest taxon index (NT) 
Table 2 Vector analysis of all environmental variables and diversity indices for TNMDS and PNMDS ordinations (Fig. 3a, b)

\begin{tabular}{|c|c|c|c|c|c|c|c|c|}
\hline \multirow[b]{2}{*}{ Variable } & \multicolumn{4}{|c|}{ TNMDS } & \multicolumn{4}{|c|}{ PNMDS } \\
\hline & Mean & Standard error & $r^{2}$ & $p$ value & Mean & Standard error & $r^{2}$ & $p$ value \\
\hline June soil moisture (\%) & 24.74 & 2.19 & 0.81 & 0.01 & 24.74 & 2.19 & 0.74 & 0.01 \\
\hline July soil moisture (\%) & 22.64 & 2.01 & 0.76 & 0.01 & 22.64 & 2.01 & 0.63 & 0.03 \\
\hline August soil moisture (\%) & 32.24 & 2.15 & 0.7 & 0.02 & 32.24 & 2.15 & 0.64 & 0.04 \\
\hline Canopy cover (densiometer, \%) & 60.26 & 6.15 & 0.58 & 0.05 & 60.26 & 6.15 & 0.53 & 0.03 \\
\hline Relative photosynthetically active radiation & 0.51 & 0.03 & 0.26 & 0.36 & 0.51 & 0.03 & 0.32 & 0.25 \\
\hline Soil pH & 5.4 & 0.13 & 0.48 & 0.11 & 5.4 & 0.13 & 0.28 & 0.31 \\
\hline Soil conductivity (mS/m) & 37.87 & 8.12 & 0.15 & 0.59 & 37.87 & 8.12 & 0.03 & 0.9 \\
\hline Slope $\left(^{\circ}\right)$ & 2.7 & 0.56 & 0.33 & 0.28 & 2.7 & 0.56 & 0.19 & 0.49 \\
\hline Species richness (S) & 58.1 & 4.67 & 0.12 & 0.66 & 58.1 & 4.67 & 0.41 & 0.15 \\
\hline Shannon-Weiner Index $\left(H^{\prime}\right)$ & 1.25 & 0.03 & 0.37 & 0.2 & 1.25 & 0.03 & 0.13 & 0.6 \\
\hline Nearest Relatedness Index (NRI) & -0.65 & 0.08 & 0.22 & 0.39 & -0.65 & 0.08 & 0.64 & 0.04 \\
\hline Nearest Taxon Index (NTI) & 0.43 & 0.05 & 0.66 & 0.03 & 0.43 & 0.05 & 0.19 & 0.49 \\
\hline
\end{tabular}

Microstegium viminium being present in every acid seep spring. However, these acid seep springs have become more similar to each other over the past 49 years (Barfknecht et al. 2020), supporting biotic homogenization. Individual acid seep springs exhibited variations in composition and within-site phylogenetic beta diversity despite the relatively high abundance of $M$. vimineum compared to native and other exotic species. Differences in within-spring alpha-diversity may explain the lack of differences in phylogenetic clustering or overdispersion within individual acid seep springs based on ANOVA, despite a gradient in phylogenetic clustering across all acid seep springs (NTI for TNMDS and NRI based on PNMDS).

Based on this study, consistent with successional species compositional changes in these acid seep springs, the plant communities have become more similar over time (Schwegman 1969; Basinger 2009; Barfknecht et al. 2020). The homogenization of plant assemblages over time following exotic plant species invasion can reduce alpha diversity and lead to increasing abundance of evolutionarily related species (i.e., phylogenetic clustering; Michelan et al. 2010; Barber et al. 2017). This homogenization of plant communities was observed among these acid seep springs over 49 years based on species presence-absence (Barfknecht et al. 2020). Since the acid seep springs are not homogenous and maintain a gradient of diversity despite exotic invasion, environmental filtering mechanisms based on abiotic conditions may be more influential in shaping community assembly than biotic effects of the invasive (Kraft et al. 2015). However, exotic invasions can alter biotic filtering and lead to an increase in phylogenetic diversity (i.e., decreasing NRI and NTI values), resulting in communities becoming phylogenetically over-dispersed as evolutionarily unrelated species come to dominate relative to evolutionarily related taxocenes (Qian and Sandel 2017; Violle et al. 2011). However, the acid seep springs were not phylogenetically over-dispersed, but were instead nearly phylogenetically neutral based on NRI, and phylogenetically clustered based on NTI. This overall pattern of phylogenetic clustering is consistent with the concept that environmental filtering shifts can result from abiotic changes over time as opposed to biotic changes due to exotic invasion (Cadotte and Tucker 2017).

The acid seep springs in 2017 had high frequencies of common, native bottomland species including Acer rubrum, Carex crinita, Corylus americana, Cornus florida, and Toxicodendron radicans, despite experiencing competition with the exotic Microstegium vimineum. This observation may indicate that restoration of the local flora to a similar condition prior to $M$. vimineum invasion may be possible with reimplemented and frequent management (herbicide applications, hand pulling, prescribed fire treatments, etc.). Corylus americana abundance has been shown to be significantly greater following a lack of prescribed fire, even between immediately consecutive years after fire treatments (White 1983). Furthermore, this shrub has increased in abundance in the seeps since previous surveys (Schwegman 1969; Basinger 2009), suggesting that the recent lack of prescribed fire management may hinder restoration efforts to treat for invasive species and restore the ecohydrology of these acid seep springs (Barfknecht et al. 2020). Prescribed fire could result in a decrease of native shrubs once common in the acid seep springs before $M$. vimineum invasion and stream downcutting occurred allowing reestablishment of native understory herbaceous species. 
While community (taxonomic) and phylogenetic compositional differences among the acid seep springs are evident, the diversity of these communities also varied. This variability is not only observed to be present currently, but also across previous surveys based on species presence-absence (Barfknecht et al. 2020). Despite invasion by an exotic grass, the acid seep spring communities exhibit a resilience to invasion as they remain distinct from each other in terms of taxonomic alpha-diversity and phylogenetic beta-diversity. The species centroid of $M$. vimineum was central within the species abundance-based ordination (Fig. 3), consistent with its presence in all sampled acid seep springs. In comparison, other systems that have experienced invasion by $M$. vimineum have shown less resilience, often mediated by altered soil nutrient cycling (Ross 2008; DeMeester and Richter 2010). Despite its high abundance, $M$. vimineum invasion did not explain differences in community composition and phylogenetic beta-diversity, among the acid seep springs. Other studies have found that a series of communities can remain compositionally distinct following invasion (Rijal et al. 2017), also in contrast to the biotic homogenization hypothesis (Olden et al. 2004; Olden and Rooney 2006). In addition, the gradient in beta-diversity among springs confirms that M. vimineum was able to invade all acid seep springs despite inherent differences in composition and diversity.

Gradients in diversity observed in the multivariate analyses only showed differences in community and phylogenetic composition based on phylogenetic diversity. Of all the diversity indices quantified, NTI (based on mean nearest neighbor distances) varied in the TNMDS ordination and NRI (based on mean pairwise distances) varied in the PNMDS ordination. These findings highlight the value of including phylogenetic measures of diversity to supplement measures of taxonomic diversity for understanding community assembly (Qian and Jin 2016; Barber et al. 2017; Khalil et al. 2017; Jones et al. 2019).

NTI indicates a gradient of phylogenetic beta-diversity across the acid seep springs with Cove and South Springs being the most phylogenetically clustered (i.e., positive NTI values) based on taxonomic composition and both observed and expected mean nearest neighbor distances. Conversely, species present in New Spring were also phylogenetically clustered based on NTI yet had less-related (but not over-dispersed) species than Cove and South Springs. Species within the species abundance-based NMDS ordination associated with the highest levels of phylogenetic clustering based on NTI in these acid seep springs included the ferns Athyrium filix-femina, and Osmunda regalis $\mathrm{L}$. The late-season, fast-growing tendency of phylogenetically conservative species such as $A$. filix-femina may contribute to this phylogenetic clustering. Phylogenetic composition shows that phylogenetic clustering based on NRI (observed and expected mean pairwise distances) was highest in New and Baldy Springs and lowest at Kruger Spring.

The two taxonomic indices $\left(S\right.$ and $\left.H^{\prime}\right)$ were positively correlated, and the two phylogenetic indices (NRI and $N T I$ ) were negatively correlated. While several studies across a broad range of taxa report that $S$ and $H^{\prime}$ are usually positively correlated (Stirling and Wilsey 2001), $N R I$ and NTI generally seem to be more independent of each other. This independence of the phylogenetic indices may be because NRI and NTI are dependent on mean pairwise distances and mean nearest taxon distances, respectively (Webb et al. 2008). Therefore, these two indices measure fundamentally different aspects of clustering and overdispersion, NTI is more sensitive to tip-level divergences in a phylogeny and NRI is more sensitive to deeper phylogenetic divergences (Webb et al. 2002). The lack of similarity between NRI and other phylogenetic indices has been observed in other forested systems (Qian et al. 2015; Qian et al. 2016). This may be because different aspects of phylogenetic diversity are more susceptible than others to differences in both climate and environmental gradients.

Based on both NMDS ordinations, overhead canopy cover and soil moisture in June, July, and August varied significantly between springs and helps explain variability in community composition. Sites with the highest overhead canopy cover also had the lowest moisture levels. For example, the species-abundance based NMDS shows that Azotus Spring had the highest canopy cover and lowest soil moisture values for all three summer months and was associated with species such as Boehmeria cylindrica (L.) Sw., Arisaema triphyllum (L.) Schott, Polystichum acrostichoides (Michx.) Schott, and Platanthera lacera (Michx.) G. Don. Boehmeria cylindrica, a wetland plant, occurred in relatively dry sites consistent with its ability to germinate in a range of wet to dry habitats (Sánchez-García et al. 2017). For the perennial arum Arisaema triphyllum, light and plant density can contribute significantly to variation in the potential for sexual reproduction (Levine and Feller 2004). In the acid seep springs, $A$. triphyllum favored seeps with relatively high canopy cover and low soil moisture levels.

Acid seep springs with the highest soil moisture during the summer months also had the lowest overhead canopy cover. These springs included Cove, South, and Sphagnum Springs. Species associated with these open wet springs included the ferns Osmunda cinnamomea L., O. regalis, and the legume Apios americana Medik. The genus Osmunda is known for its extreme preference for wet conditions, and O. cinnamomea is one of the most wetland obligate species occurring within the acid seep springs considered in this study ( $\mathrm{Xu}$ and Deng 2017). Limited research exists on how Apios americana 
occurrence varies based on soil moisture and light heterogeneity, but its occurrence has been noted within habitats with similar dominant species such as Acer rubrum and Liriodendron tulipifera (Boyd and Monroe 2010).

Environmental filtering, such as stream down-cutting (the downward cutting of a streambed which can cause reductions in the water table), was also involved in determining which species coexisted and assembled into these communities. The resulting differences in competitiveness among the species in response to environmental filtering can often exclude more distantly related taxa, even when the traits underlying the relevant species differences are phylogenetically conserved (Mayfield and Levine 2010). This process of environmental filtering and phylogenetic clustering of coexisting species can ultimately influence the distribution patterns of species (Singer et al. 2018). These observations support the idea that environmental filtering changes the competitive interactions among coexisting native and exotic species, causing community and phylogenetic compositional shifts in the acid seep springs. Local-scale community assembly rules can be modeled by inspecting how regional-level native species traits interact with community and environmental filters to affect species presence and abundance (Pearson et al. 2018). In addition, some exotics may follow similar community assembly rules as natives, while those exhibiting novel interactions with native species and community filters perform differently compared to natives. Exotic species are subject not only to the environmental filters which partially determine their presence and abundance, but they can cause shifts in these parameters for native species.

\section{Conclusion}

Acid seep springs remained taxonomically and phylogenetically unique from each other after the invasion of Microstegium vimineum. Community and phylogenetic compositional differences between acid seep springs were explained by soil moisture and canopy cover as environmental variables as well as phylogenetic clustering patterns within individual acid seep springs. In addition, acid seep springs, which had greater canopy cover, also typically had drier soils, and this abiotic gradient leads to certain species occupying different acid seep springs. Continued surveys monitoring species composition within these acid seep springs will allow for temporal changes to be documented. It would also be valuable to document the distinctiveness of these seep springs in comparison to the surrounding forest matrix. Acid seep spring community and phylogenetic composition appears to be driven more through environmental filtering by altered abiotic variables than by the altered biotic competitive effects following Microstegium vimineum invasion. These phenomena support the concepts of Elton's biotic resistance hypothesis while previous research shows support for the biotic homogenization hypothesis. Both taxonomic and phylogenetic diversity metrics were of value in helping to understand how acid seep spring communities are unique, despite recent exotic invasion. While taxonomic indices reflect differences in species occurrence among seeps, phylogenetic diversity indicated that these differences were related to the occurrence of evolutionarily related groups of species. These differences show the analytical value of not only including both taxonomic and phylogenetic data when assessing the effects of exotic invasion, but that both univariate and multivariate statistical analyses are crucial for ecological, conversational, and potentially restoration-based approaches.

\section{Supplementary Information}

The online version contains supplementary material available at https://doi. org/10.1186/s13717-020-00272-3.

Additional file 1: Figure S1. Ten acid seep springs surveyed in the Cretaceous Hills region of Southern Illinois.

Additional file 2: Table S1. Average percent abundance of species observed from 2017 transect data. Species codes used for phylogeny (Fig. 1) and NMDS ordination (Fig. 3a) provided. Frequency indicates the number of acid seep springs each species occurred in. Mean values were calculated from the midpoints of Daubenmire cover classes estimated from 20 random $1-\mathrm{m}^{2}$ plots established along transects in each acid seep spring.

\section{Abbreviations}

AIC: Akaike information criterion; ANOVA: Analysis of variance;

AugSM: August soil moisture; Den: Overhead canopy cover (measured via a densiometer); GPS: Global Positioning System; H': Shannon-Weiner Diversity Index; JulSM: July soil moisture; JunSM: June soil moisture; LSD: Least significant difference; NMDS: Non-metric multi-dimensional scaling; NRI: Net Relatedness Index; NTI: Nearest Taxon Index; PAR: Photosynthetically active radiation; PERMANOVA: Permutational analysis of variance; PERMDISP: Tests of homogeneity of dispersion; PNMDS: Phylogenetically-based multidimensional scaling; S: Species richness; TNMDS: Taxonomically-based multidimensional scaling

\section{Acknowledgements}

We would like to extend our gratitude to Nicholas Seaton, Kevin Rohling, Chris Evans, and Jody Shimp for assistance in field research; Loretta Battaglia for assistance in result interpretation and analysis; and Phillip Dummeier for allowing access on and close to his private property. We would also like to thank John Schwegmann and Mark Basinger for their previous survey work in these unique plant communities.

\section{Authors' contributions}

David Barfknecht conducted surveys in the summer of 2017; conducted all phylogenetic, community, and statistical analyses; and led writing of the manuscript. David Gibson helped develop the initial study design, assisted in determining the appropriate analytical procedures, and contributed to writing and editing the manuscript. The authors read and approved the final manuscript.

\section{Authors' information}

David Barfknecht is a doctoral student in David Gibson's lab at Southern Illinois University - Carbondale. His research interests are community, invasion, and metacommunity ecology. David Gibson is a professor of Plant Biology SIUC. His research interests are in the vegetation ecology of grasslands and forest-grassland mosaics. 


\section{Availability of data and materials}

Data used in the analyses for this manuscript are provided in a supplemental file provided in tables at the following link: 10.6084/m9.figshare.7127693/. Here, the raw community and environmental variable data files, the list of accession numbers for nucleotides used in the phylogenetic tree creation and analysis, and the R script used to perform all univariate and multivariate statistical analyses are provided.

\section{Ethics approval and consent to participate}

Not applicable.

\section{Consent for publication}

Not applicable.

\section{Competing interests}

The authors declare that they have no competing interests.

Received: 2 July 2020 Accepted: 15 November 2020

Published online: 05 January 2021

\section{References}

Barber NA, Jones HP, Duvall MR, Wysocki WP, Hansen MJ, Gibson DJ (2017) Phylogenetic diversity is maintained despite richness losses over time in restored tallgrass prairie plant communities. J Appl Ecol 54:137-144

Barfknecht DF, Gibson DJ, Neubig KM (2020) Plant community and phylogenetic shifts in acid seep springs over 49 years following Microstegium vimineum invasion. Plant Ecol 221:1-9

Basinger MA (2009) Survey of some seep springs in the Cretaceous Hills of Pope and Massac Counties in Southern Illinois. Southern Illinois University Press, Carbondale, IL

Bonham CD, Mergen DE, Montoya S (2004) Plant cover estimation: a contiguous Daubenmire frame. Rangelands 26:17-22

Boyd AE, Monroe AL (2010) Vascular flora of the Warren Wilson College Campus, Swannanoa, North Carolina. Castanea 75:353-365

Byers JE, Noonburg EG (2003) Scale dependent effects of biotic resistance to biological invasion. Ecology 84:1428-1433

Cadotte MW, Tucker CM (2017) Should environmental filtering be abandoned? Trends Ecol Evol 32:429-437

Cranfill R (1991) Flora of Hardin County, Kentucky. Castanea 56:228-267

D'Antonio C, Flory SL (2017) Long-term dynamics and impacts of plant invasions. J Ecol 105:1459-1461

D'Antonio CM, Vitousek PM (1992) Biological invasions by exotic grasses, the grass/fire cycle, and global change. Annu Rev Ecol Syst 23:63-87

Daubenmire R (1959) A canopy-coverage method of vegetational analysis. Northwest Sci 33:43-64

Davis MA (2003) Biotic globalization: does competition from introduced species threaten biodiversity? Bioscience 53:481-489

DeMeester JE, Richter D (2010) Differences in wetland nitrogen cycling between the invasive grass Microstegium vimineum and a diverse plant community. Ecol Appl 20:609-619

Edgar RC (2004) MUSCLE: multiple sequence alignment with high accuracy and high throughput. Nucleic Acids Res 32:1792-1797

Elton CS (1958) The ecology of invasions by animals and plants. Methuen, London, UK

Emery SM, Flory SL, Clay K, Robb JR, Winters B (2013) Demographic responses of the invasive annual grass Microstegium vimineum to prescribed fires and herbicide. For Ecol Manag 308:207-213

Flory SL, Clay K (2010) Non-native grass invasion alters native plant composition in experimental communities. Biol Invasions 12:1285-1294

Flory SL, Lewis J (2009) Nonchemical methods for managing Japanese stiltgrass (Microstegium vimineum). Invasive Plant Sci Manage 2:301-308

Flory SL, Rudgers JA, Clay K (2007) Experimental light treatments affect invasion success and the impact of Microstegium vimineum on the resident community. Nat Areas J 27:124-132

Fox J, Weisberg S (2011) An $\{R\}$ Companion to Applied Regression. Sage, Thousand Oaks, CA

Fox MD, Fox BJ (1986) The susceptibility of natural communities to invasion. Ecology of biological invasions. Cambridge University Press, Cambridge, UK

Frey M, Schmit JP (2015) Suppressing Japanese Stiltgrass (Microstegium vimineum) with the grass-specific herbicide Sethoxydim. Nat Areas J 35: 585-589
Gibson DJ, Spyreas G, Benedict J (2002) Life history of Microstegium vimineum (Poaceae), an invasive grass in southern Illinois. J Torrey Bot Soc 129:207-219

González-Moreno P, Diez JM, Ibáñez I, Font X, Vilà M (2014) Plant invasions are context-dependent: multiscale effects of climate, human activity, and habitat. Divers Distrib 20:720-731

Gouy M, Guindon S, Gascuel O (2010) SeaView version 4: a multiplatform graphical user interface for sequence alignment and phylogenetic tree building. Mol Biol Evol 27:221-224

Gu X, Fu YX, Li W (1995) Maximum likelihood estimation of the heterogeneity of substitution rate among nucleotide sites. Mol Biol Evol 12:546-557

Heikens AL, Robertson PA (1995) Classification of barrens and other natural xeric forest openings in southern Illinois. Bull Torrey Bot Club 122:203-214

Homoya MA, Abrell DB, Aldrich JA, Post TW (1984) The natural regions of Indiana. Proc Indiana Acad Sci 94:245-268

Horton JL, Neufeld HS (1998) Photosynthetic responses of Microstegium vimineum (Trin.) A. Camus, a shade-tolerant, C4 grass, to variable light environments. Oecologia 114:11-19

Hothorn T, Bretz F, Westfall P (2008) Simultaneous inference in genera parametric models. Biom J 50:346-363

Huebner CD (2007) Strategic management of five deciduous forest invaders using Microstegium vimineum as a model species. In: Cavender ND (ed) Proceedings of the 2007 Ohio invasive plants research conference: continuing partnerships for invasive plant management; 2007 January 18; Delaware, OH. Ohio Biological Survey, Columbus, OH, pp 19-28

Jones HP, Barber NA, Gibson DJ (2019) Is phylogenetic and functional trait diversity a driver or a consequence of grassland community assembly? J Ecol 107:2027-2032

Kalyaanamoorthy S, Minh BQ, Wong TK, von Haeseler A, Jermiin LS (2017) ModelFinder: fast model selection for accurate phylogenetic estimates. Nat Methods 14:587

Kembel SW, Cowan PD, Helmus MR, Cornwell WK, Morlon H, Ackerly DD, Blomberg SP, Webb CO (2010) Picante: R tools for integrating phylogenies and ecology. Bioinformatics 26:1463-1464

Khalil MI, Gibson DJ, Baer SG (2017) Phylogenetic diversity reveals hidden patterns related to population source and species pools during restoration. J Appl Ecol 54:91-101

Kraft NJ, Adler PB, Godoy O, James EC, Fuller S, Levine JM (2015) Community assembly, coexistence and the environmental filtering metaphor. Funct Ecol 29:592-599

Leicht SA, Silander JA, Greenwood K (2005) Assessing the competitive ability of Japanese stilt grass, Microstegium vimineum (Trin.) A. Camus. J Torrey Bot Soc 132:573-580

Lenth RV (2016) Least-squares means: The R Package Ismeans. J Stat Softw $69: 1-33$

Levine JM, D'Antonio CB (1999) Elton revisited: a review of evidence linking diversity and invasibility. Oikos 87:15-26

Levine MT, Feller IC (2004) Effects of forest age and disturbance on population persistence in the understory herb, Arisaema triphyllum (Araceae). Plant Ecol 172:73-82

Maddison WP and Maddison DR (2018) Mesquite: a modular system for evolutionary analysis. Version 3.40. Retrieved from http://mesquiteproject.org. Accessed 8 Aug 2019

Mayfield MM, Levine JM (2010) Opposing effects of competitive exclusion on the phylogenetic structure of communities. Ecol Lett 13:1085-1093

Merten GH, Welch HL, Tomer MD (2016) Effects of hydrology, watershed size, and agricultural practices on sediment yields in two river basins in lowa and Mississippi. J Soil Water Conserv 71:267-278

Michelan TS, Thomaz S, Mormul RP, Carvalho P (2010) Effects of an exotic invasive macrophyte (tropical signalgrass) on native plant community composition, species richness and functional diversity. Freshw Biol 55: 1315-1326

Odegard $J L$ (2017) The role of functional diversity in biotic resistance of nonnative fishes and invertebrates in Lake Erie coastal wetlands. Doctoral dissertation, The Ohio State University

Oksanen J, Kindt R, Legendre P, O'Hara B, Stevens MHH, Oksanen MJ, Suggests MASS (2007) The vegan package. Commun Ecol Package 10:631-637

Olden JD, Poff NL, Douglas MR, Douglas ME, Fausch KD (2004) Ecological and evolutionary consequences of biotic homogenization. Trends Ecol Evol 19: $18-24$

Olden JD, Rooney TP (2006) On defining and quantifying biotic homogenization Glob Ecol Biogeogr 15:113-120 
Oswalt CM, Oswalt SN, Clatterbuck WK (2007) Effects of Microstegium vimineum (Trin.) A. Camus on native woody species density and diversity in a productive mixed-hardwood forest in Tennessee. For Ecol Manag 242:727-732

Paradis E, Claude J, Strimmer K (2004) APE: analyses of phylogenetics and evolution in R language. Bioinformatics 20:289-290

Parker JD, Hay ME (2005) Biotic resistance to plant invasions? Native herbivores prefer non-native plants. Ecol Lett 8:959-967

Pearson DE, Ortega YK, Eren Ö, Hierro JL (2018) Community assembly theory as a framework for biological invasions. Trends Ecol Evol 33:315-325

Pimm SL, Pimm SL (1991) The balance of nature? Ecological issues in the conservation of species and communities. University of Chicago Press, Chicago, IL

Pisula NL, Meiners SJ (2010) Relative allelopathic potential of invasive plant species in a young disturbed woodland. J Torrey Bot Soc 137:81-87

Qian H, Field R, Zhang JL, Zhang J, Chen S (2016) Phylogenetic structure and ecological and evolutionary determinants of species richness for angiosperm trees in forest communities in China. J Biogeogr 43:603-615

Qian H, Jin Y (2016) An updated megaphylogeny of plants, a tool for generating plant phylogenies and an analysis of phylogenetic community structure. J Plant Ecol 9:233-239

Qian H, Sandel B (2017) Phylogenetic relatedness of native and exotic plants along climate gradients in California, USA. Divers Distrib 23:1323-1333

Qian H, Wiens JJ, Zhang J, Zhang Y (2015) Evolutionary and ecological causes of species richness patterns in North American angiosperm trees. Ecography 38 241-250

Rejmánek M (1996) Species richness and resistance to invasions. In: Biodiversity and ecosystem processes in tropical forests. Springer, Berlin, Heidelberg

Ricciardi A (2001) Facilitative interactions among aquatic invaders: is an "invasional meltdown" occurring in the Great Lakes? Can J Fish Aquat Sci 58: 2513-2525

Rijal DP, Alm T, Nilsen L, Alsos IG (2017) Giant invasive Heracleum persicum: Friend or foe of plant diversity? Ecol Evol 7:4936-4950

Rooney TP, Olden JD, Leach MK, Rogers DA (2007) Biotic homogenization and conservation prioritization. Biol Conserv 134:447-450

Rooney TP, Wiegmann SM, Rogers DA, Waller DM (2004) Biotic impoverishment and homogenization in unfragmented forest understory communities. Conserv Biol 18:787-798

Ross KA (2008) The effects of soil manipulations on invasion success of two exotic species, Japanese barberry (Berberis thunbergii) and Japanese stiltgrass (Microstegium vimineum). Doctoral dissertation, Rutgers University-Graduate School-New Brunswick

Sánchez-García EA, Rodríguez-Medina K, Moreno-Casasola P (2017) Effects of soil saturation and salinity on seed germination in seven freshwater marsh species from the tropical coast of the Gulf of Mexico. Aquat Bot 140:4-12

Schwegman JE (1969) Vegetation of some seep springs in the Cretaceous Hills region of southern Illinois. Master's thesis. Southern Illinois University, Carbondale, IL

Singer D, Kosakyan A, Seppey CV, Pillonel A, Fernández DL, Fontaneto D, Lara E (2018) Environmental filtering and phylogenetic clustering correlate with the distribution patterns of cryptic protist species. Ecology 99:904-914

Southern Illinois Native Plant Society. 2019. https://www.rtrcwma.org/projects/ striketeam/. Accessed 8 Aug 2019

Springer GS, Poston HA, Hardt B, Rowe HD (2015) Groundwater lowering and stream incision rates in the Central Appalachian Mountains of West Virginia, USA. Int J Speleol 44:99-116

Stirling G, Wilsey B (2001) Empirical relationships between species richness, evenness, and proportional diversity. Am Nat 158:286-299

Strayer DL (2012) Eight questions about invasions and ecosystem functioning. Ecol Lett 15:1199-1210

Tavaré S (1986) Some probabilistic and statistical problems in the analysis of DNA sequences. Lectures on Mathematics in the Life Sciences 17:57-86

Violle C, Nemergut DR, Pu Z, Jiang L (2011) Phylogenetic limiting similarity and competitive exclusion. Ecol Lett 14:782-787

Voigt JW, Mohlenbrock RH (1964) Plant Communities of Southern Illinois. Southern Illinois University Press, Carbondale, IL

Von Holle B (2005) Biotic resistance to invader establishment of a southern Appalachian plant community is determined by environmental conditions. J Ecol 93:16-26
Walther GR, Roques A, Hulme PE, Sykes MT, Pyšek P, Kühn I, Czucz B (2009) Alien species in a warmer world: risks and opportunities. Trends Ecol Evol 24:686-693

Ward JS, Mervosh TL (2012) Nonchemical and herbicide treatments for management of Japanese stiltgrass (Microstegium vimineum). Invasive Plant Sci Manage 5:9-19

Warren RJ, Bahn V, Kramer TD, Tang Y, Bradford MA (2011) Performance and reproduction of an exotic invader across temperate forest gradients. Ecosphere 2:14

Webb CO, Ackerly DD, and Kembel SW (2008) Phylocom: software for the analysis of phylogenetic community structure and trait evolution. Version 4.0.1.

Webb CO, Ackerly DD, McPeek MA, Donoghue MJ (2002) Phylogenies and community ecology. Annu Rev Ecol Syst 33:475-505

White AS (1983) The effects of thirteen years of annual prescribed burning on a Quercus ellipsoidalis community in Minnesota. Ecology 64:1081-1085

Wickham H (2009) ggplot2: Elegant graphics for data analysis. Springer-Verlag, New York, NY

Xu Z, Deng M (2017) Osmundaceae. Identification and control of common weeds $2: 11-15$

Yang Z (1994) Maximum likelihood phylogenetic estimation from DNA sequences with variable rates over sites: approximate methods. J Mol Evol 39:306-314

Yannelli FA, Koch C, Jeschke JM, Kollmann J (2017) Limiting similarity and Darwin's naturalization hypothesis: understanding the drivers of biotic resistance against invasive plant species. Oecologia 183:775-784

Zharkikh A (1994) Estimation of evolutionary distances between nucleotide sequences. J Mol Evol 39:315-329

\section{Publisher's Note}

Springer Nature remains neutral with regard to jurisdictional claims in published maps and institutional affiliations.

\section{Submit your manuscript to a SpringerOpen ${ }^{\circ}$ journal and benefit from:}

- Convenient online submission

- Rigorous peer review

- Open access: articles freely available online

- High visibility within the field

- Retaining the copyright to your article

Submit your next manuscript at $>$ springeropen.com 